\title{
CONCILIAÇÃO ENTRE TRABALHO E VIDA FAMILIAR: UM DEBATE NECESSÁRIO ${ }^{1}$
}

\section{RECONCILIATION BETWEEN WORK AND FAMILY LIFE: A NECESSARY DEBATE}

\author{
Patricia Maccarini Moraes ${ }^{2}$ \\ Kênia Cristina Lopes Abrão ${ }^{3}$ \\ Regina Célia Tamaso Mioto ${ }^{4}$
}

\begin{abstract}
RESUMO
O avanço do capitalismo alterou as relações de trabalho e novas demandas foram colocadas às famílias. A participação das mulheres no mercado de trabalho e os debates propostos pelo feminismo conferiu relevância às políticas de conciliação entre trabalho e família. Este trabalho busca pontuar aspectos referentes ao desafio das famílias em equilibrar trabalho remunerado e não remunerado. Instigar esse debate no campo do Serviço Social é urgente, pois os assistentes sociais se defrontam com os conflitos gerados nas relações entre trabalho e família, inseridos no campo das políticas de seguridade social, que exaltam o papel da família na proteção de seus membros.
\end{abstract}

PALAVRAS-CHAVE: Família. Trabalho. Políticas de conciliação.

\section{ABSTRACT}

The advance of capitalism changed labor relations and new demands were placed to families. The participation of women in the labor market and debates proposed by feminism gave relevance to policies to reconcile work and family. This work aims scoring aspects related to the challenge of families to cope with paid and unpaid work. Instigating this debate in the field of social work is urgent since social workers are faced with conflicts triggered between work and family, in the field of social security policies, which enhance the role of the family in protecting their members.

KEYWORDS: Family. Work. Policies to reconcile. Social Work.

\footnotetext{
${ }^{1}$ O presente trabalho é parte da pesquisa Política Social, Família e Trabalho Familiar: proposições e percursos analíticos / CNPq- processo 304540/2013-7. Foi apresentado originalmente no XIV Encontro Nacional de Pesquisadores (ENPESS), realizado em Natal/RN em dezembro de 2014.

${ }^{2}$ Assistente Social do Instituto Federal de Santa Catarina, Campus Canoinhas. Mestranda em Serviço Social pelo Programa de Pós-Graduação da Universidade Federal de Santa Catarina (UFSC).

Pesquisadora integrante do Núcleo de Pesquisa Interdisciplinar Sociedade, Família e Política Social NISFAPS / UFSC. Telefone 5547 92340244, e-mail: patymacarini@hotmail.com.

${ }^{3}$ Assistente Social. Doutoranda do Programa de Pós-graduação em Serviço Social da Universidade Federal de Santa Catarina (UFSC). Pesquisadora do Núcleo de Pesquisa Interdisciplinar Sociedade, Família e Política Social - NISFAPS / UFSC. E-mail: kabrao@yahoo.com.br.

${ }^{4}$ Professora do Programa de Pós-Graduação em Política Social da Universidade Católica de Pelotas (UCPEL). Professora Colaboradora do Programa de Pós-Graduação em Serviço Social da Universidade Federal de Santa Catarina (UFSC). Bolsista de Produtividade em Pesquisa do CNPq (A2) membro do Núcleo de Pesquisa Interdisciplinar Sociedade, Família e Política Social - NISFAPS / UFSC. Telefone 55 48 3271-6514, e-mail regina.mioto@gmail.com.
} 


\section{INTRODUÇÃO}

O avanço do modo de produção capitalista alterou as relações de trabalho e com isso novas demandas foram colocadas às famílias. A crise estrutural do capitalismo, o aumento em larga escala do desemprego e o aviltamento dos salários e dos direitos do trabalho para aqueles que permanecem empregados, concomitantemente com o avanço da produção e do consumo, alteraram os padrões de renda familiar adquirida pela venda da força de trabalho masculina. Assim, a mulher é incorporada ao universo da produção, mas inserida em ocupações consideradas femininas, com contratos precários e, quando não, geralmente com remuneração inferior à dos homens. Com essas transformações, a participação da mulher no mercado de trabalho altera significativamente o modelo tradicional de família "homem-provedor/mulher-dona de casa", colocando a necessidade de reorganizar a prestação de cuidados, seja mediante serviços públicos ou privados, seja por novas articulações intrafamiliares.

No que se refere às alterações nos processos e relações de produção, constata-se a flexibilização dos processos produtivos e das relações de trabalho que trazem à tona a informalidade, a subcontratação, os trabalhadores temporários com restrição dos direitos trabalhistas, entre outros. O processo de alteração nas relações de produção tem como objetivo fundamental atender às necessidades específicas de manutenção do sistema capitalista de produção. No contexto desta configuração, Braverman (1976) aponta que desde os primórdios do capitalismo o poder do Estado é empregado para impulsionar o seu desenvolvimento, não sendo este um aspecto peculiar da sua fase monopolista, e perpetua-se, assim, a crescente distribuição desigual de propriedade. Portanto, é intrínseca a esse processo a intervenção do Estado na vida social, que se transforma ao longo da história e ocorre por meio de lógicas diversas que buscam responder às crises do próprio sistema capitalista.

Na história recente do Brasil, a adoção do modelo neoliberal colocou em movimento uma lógica de intervenção estatal no campo da vida social pautada especialmente em processos de privatização e focalização da política social.

Há o aumento expressivo de serviços pelo mercado e a família é "redescoberta" como agente privado de proteção social. O resultado deste processo comprova a sobrecarga das famílias, especialmente aquelas (em geral as mais pobres) que, sem condições de recorrer ao mercado, distribuem internamente as demandas de reprodução e de cuidados.

Serv. Soc. \& Saúde, Campinas, SP v. 14, n. 1 (19), p. 105-118, jan./jun. 2015 ISSN 1676-6806 
As mudanças observadas na organização do trabalho, com precárias condições, queda nos rendimentos obtidos pela venda da força de trabalho, além da ênfase na responsabilidade da família pela proteção social, indica a lacuna existente no debate sobre os processos de responsabilização da família, que acarreta, dentre outras coisas, a tensão para conciliar trabalho e vida familiar.

Com a progressão da participação das mulheres no mercado de trabalho e dos debates propostos no campo dos movimentos feministas, vai se conferindo relevância às denominadas políticas de conciliação entre trabalho e responsabilidades familiares. Assim, cresce o movimento para a inclusão dessa questão na agenda governamental de vários países, pois, embora as mulheres passem a compartilhar com os homens o papel de prover renda, não ocorre nem uma distribuição equilibrada e igualitária das tarefas domésticas no âmbito familiar, nem a oferta de serviços públicos suficientes para contemplar essa nova realidade.

Essa problemática vem sendo debatida em vários países europeus, onde há um variado leque de estudiosos sobre o tema, e também tem atraído a atenção de movimentos sociais, de governos, além de organizações como a Organização Internacional do Trabalho (OIT). Assim, nas últimas décadas, tem-se dado visibilidade a essa temática e tenta-se chamar a atenção de instituições estatais para que sejam desenhadas e implementadas medidas de conciliação, embora com focos analíticos e interpretativos bastante heterogêneos.

O desenho deste cenário demarca a inegável necessidade de instigar este debate no âmbito das políticas sociais e das profissões que atuam nesse campo, como o Serviço Social. Nesse sentido, o presente trabalho tem como objetivo pontuar alguns aspectos referentes ao desafio das famílias em equilibrar o trabalho remunerado e o trabalho não remunerado. Para tanto, está organizado em dois itens: o primeiro trata brevemente do contexto que torna as políticas de conciliação vida laboral e vida familiar uma questão importante. O segundo realiza uma aproximação do debate acerca das políticas de conciliação, a fim de incitar a discussão e enriquecer o diálogo no interior do Serviço Social. Posteriormente, as considerações finais. 


\section{O CONTEXTO DO DEBATE}

Nas últimas décadas verificaram-se alterações nas formas de viver em sociedade, provocadas principalmente por mudanças nas formas de produção. Essas transformações resultaram de tentativas do capital para encontrar saídas para as próprias - e constantes - crises. Na passagem do sistema fordista/taylorista para a acumulação flexível, processo iniciado por volta de 1970, buscou-se manter o padrão de lucro capitalista, o que demarcou a reestruturação produtiva em diversos setores da economia. Como o modelo fordista de pleno emprego não se sustentou, necessitava-se de mais flexibilidade para garantir a produtividade e os lucros. Assim, novos tipos de contrato de trabalho surgiram, porém com o concomitante aumento do contingente de desempregados, subempregados, trabalhadores temporários, trabalhadores em domicílio, entre outras formas precarizadas de contratação (ANTUNES, 1997).

Nesse contexto, cresceu o contingente de empregados no setor de serviços ${ }^{5}$, com acentuada redução do número de operários nos parques fabris, heterogeneização do trabalho e crescente inserção do trabalho feminino no mundo operário, uma subproletarização que, nos termos de Antunes (1997), é caracterizada pela "expansão do trabalho parcial, temporário, precário, subcontratado, 'terceirizado', que marca a sociedade dual no capitalismo avançado [grifos das autoras]" (ibid., p. 41), sendo o desemprego estrutural um dos resultados que ainda se reafirma.

Os efeitos das crises, a exemplo, colocaram fim ao padrão keynesianista, nos anos de 1980, e trouxeram à cena os padrões liberais por meio do neoliberalismo. Este representou um Estado forte, mas contido nos gastos sociais; diminuíram-se as ações de garantia de bem-estar social, ou seja, restringiram-se os direitos sociais e foram desmontadas as políticas sociais que estavam em fase de estruturação no Brasil. De acordo com Soares (2002), a crise do Estado capitalista deu-se a partir do intenso processo de internacionalização dos mercados e dos sistemas produtivos e da tendência à unificação monetária e financeira, o que reduziu a autonomia dos Estados Nacionais (SOARES, 2002). Para a autora, a maioria dos países inseridos nesse processo

\footnotetext{
${ }^{5}$ No âmbito da economia mundial, pode-se considerar que uma das mudanças mais relevantes introduzidas no cotidiano no século XX é a expansão das atividades de serviços. Nas últimas décadas, na economia brasileira, o setor de serviços representa uma trajetória equivalente ao crescimento da econômica dos países desenvolvidos, configura quase dois terços de emprego urbano metropolitano e responde por mais da metade do PIB (MELLO et. al.,1998) Serv. Soc. \& Saúde, Campinas, SP v. 14, n. 1 (19), p. 105-118, jan./jun. 2015 ISSN 1676-6806
} 
caracterizou-se pela: ampliação da abertura econômica para o exterior, racionalização da participação do Estado na economia, liberalização dos mercados, preços e atividades produtivas e estabilização dos preços. Esse ajuste não foi somente de natureza econômica, mas também "faz parte de uma redefinição global do campo políticoinstitucional e das relações sociais" (SOARES, 2002, p. 12).

A partir da década de 1990, assistiu-se a mudanças econômicas e sociais sob os ditames do neoliberalismo, que "promove o acirramento da destituição social, da pobreza e das mais diversas situações de precariedade alterando, portanto, as formas de organização da reprodução social dos trabalhadores e suas famílias" (ALENCAR, 2010, p. 6). Para além das condições de trabalho, as condições de vida dos indivíduos são definidas pela inserção dos membros da família no mercado de trabalho, que articula alternativas para a superação das condições de pobreza, caracterizando a família como unidade de renda e consumo (ALENCAR, 2010). Nesse cenário de precarização das relações de trabalho e de encolhimento das políticas sociais, as famílias são vistas como suporte para seus membros e também com a possibilidade de transformar suas condições de vida.

Enquanto a intervenção estatal é diminuída e o mercado se impõe como regente primordial e há uma forte presença da ideologia que incentiva o individualismo. Os direitos sociais conquistados arduamente e a concepção de cidadania ficam restritos e as políticas sociais são focalizadas na população mais pobre.

Concomitante, as alterações nas formas de produção expandiram-se, alcançando as relações estabelecidas entre os indivíduos e as famílias. Assim, à precarização das relações de trabalho, os espaços de reprodução social são profundamente afetados. Em relação às famílias, uma das principais alterações vivenciadas foi a maciça inserção das mulheres no mercado de trabalho. De uma taxa de participação feminina no mercado de trabalho de 18,6\%, em 1970, saltou-se para 48,9\% em 2010. A taxa de participação masculina no mercado de trabalho, ao contrário, caiu de $71,8 \%$ para $67,1 \%$, no mesmo intervalo de tempo. Essas alterações podem ser conferidas na tabela 1.

A inserção das mulheres no trabalho, embora possa atender em alguma medida às necessidades financeiras dos grupos familiares, altera as formas de garantia privada de proteção, o que se torna problemático, pois a família sempre assumiu papel proeminente na provisão de bem-estar. 
Tabela 1 - Taxa de participação feminina e masculina no mercado de trabalho

\begin{tabular}{|l|c|c|c|c|c|}
\hline \multicolumn{7}{|c|}{ Mulher } \\
\hline & 1970 & 1980 & 1991 & 2000 & 2010 \\
\hline PIA & 33.305 .630 & 44.456 .730 & 57.612 .439 & 70.058 .774 & 83.223 .618 \\
\hline PEA & 6.195 .447 & 11.842 .726 & 18.966 .712 & 30.921 .054 & 40.678 .651 \\
\hline Taxa de participação (\%) & 18,6 & 26,6 & 32,9 & 44,1 & 48,9 \\
\hline \multicolumn{7}{|c|}{ Homem } & \multicolumn{4}{c|}{2010} \\
\hline \multicolumn{7}{|c|}{1970} & 1980 & 1991 & 2000 & 200 \\
\hline PIA & 32.556 .489 & 43.354 .466 & 55.247 .139 & 66.851 .584 & 78.757 .680 \\
\hline PEA & 23.391 .777 & 31.392 .986 & 39.489 .091 & 46.546 .419 & 52.826 .008 \\
\hline Taxa de participação (\%) & 71,8 & 72,4 & 71,5 & 69,6 & 67,1 \\
\hline
\end{tabular}

Fonte: Censo Demográfico 1970 (tabela 24, p. 93). Disponível em:

http://biblioteca.ibge.gov.br/visualizacao/periodicos/69/cd_1970_v1_br.pdf).

Censo Demográfico 1970 (tabela 1.1 p. 2). Disponível em:

http://biblioteca.ibge.gov.br/visualizacao/periodicos/75/cd_1980_v1_t5_n1_br.pdf).

Censos Demográficos 1991, 2000 e 2010. Disponíveis no SIDRA/IBGE (tabela 616).

Campos e Mioto (2003), na esteira da formulação de Esping-Andersen (2000) e Saraceno (1996), apontam o caráter familista que preside o desenvolvimento dos sistemas de proteção social na América Latina, especialmente no Brasil, e a sua acentuação a partir dos anos de 1990. Na análise de Martin (1995), a família foi redescoberta como um importante "manancial natural de solidariedade alternativa às do Estado, como um tecido de laços sociais elementares, [...] um escudo protetor quando falham outros modelos de integração" (ibid., p. 70-71). O autor esclarece que práticas de solidariedade familiar e intergeracional sempre foram presentes; contudo, nesta súbita "redescoberta" da família como importante instância de cuidados, tais práticas são empregadas para enfrentamento da "crise" da provisão pública de proteção social. A tendência seria restringir a dependência da família dos serviços públicos de bem-estar e fazer dela uma unidade econômica e política de resolução de problemas e provisão do bem-estar de seus membros, sem o suporte do Estado.

Em suma, "na formação capitalista sob a égide do liberalismo, a família se conforma como o espaço privado por excelência e, como espaço privado, deve responder pela proteção social de seus membros" (MIOTO, 2008, p. 133). A autora avalia, porém, que a família não tem condições objetivas de realizá-la e por isso insiste que, quando se trata de provisão de bem-estar, a presença do Estado é fundamental por meio das políticas sociais. Embora o campo das relações que envolvem famílias e 
política social seja obscuro e contraditório, esta última é um recurso importante para a produção do bem-estar das primeiras, sobretudo quando se trata dos serviços referentes à organização da vida familiar e suas implicações no trabalho de reprodução (MIOTO, 2012).

Nesse contexto permeado por mudanças nas esferas do trabalho e da família, marcado por desigualdades sociais, além da débil presença do Estado na provisão de bem-estar, configuram-se notáveis conflitos entre vida familiar e vida laboral. Estes conflitos repercutem negativamente na vida das pessoas e sobre as condições de trabalho. Sorj (2004) alerta que "é na interação entre as mudanças na estrutura das famílias e as mudanças no mercado de trabalho que permite identificar os novos desafios que as famílias enfrentam para alcançar o equilíbrio entre essas duas esferas" (ibid., p. 15). Destaca-se que, diante da maciça inserção das mulheres no mercado de trabalho, somada às alterações na organização da família, faz-se emergente que "a sociedade redefina a forma como as responsabilidades familiares serão atendidas" (ibid., p. 2).

\section{AS RELAÇÕES FAMÍlia E TRABALHO E AS POLÍticAS DE CONCILIAÇÃO}

Nas últimas décadas, como foi demonstrado, cresceu significativamente a participação da mulher no mercado de trabalho e a renda obtida pelo seu trabalho tornou-se fundamental para o sustento da família. No entanto, vários estudos apontam que esse processo não foi acompanhado de mudanças nas funções que a mulher tradicionalmente desempenha, mantendo-se a divisão tradicional do trabalho na família. Astelarra (2007), a partir de pesquisa realizada na Espanha, aponta que

[...] as mulheres de todas as gerações continuam sendo responsáveis pelo trabalho não remunerado. Não só isso: a participação no mercado de trabalho não mudou as próprias dimensões de gênero e, as mulheres, especialmente no caso da geração mais jovem, têm problemas de desemprego, diferença de salários e tipos de empregos para elas (ibid., p. 75).

Pesquisas que buscaram apreender a parcela do tempo de homens e mulheres dedicada aos afazeres domésticos demonstram que a carga horária dedicada pelas mulheres é superior à dos homens. Os estudos de Bruschini (2007) referentes ao contexto brasileiro concluíram que 
[...] as mulheres, muito mais do que os homens, dedicam parte significativa de seu tempo ao trabalho para a reprodução social: são as cônjuges, principalmente as mães, aquelas que dedicam número mais elevado de horas semanais aos afazeres domésticos; e, entre as que tiveram filhos, são as mães de filhos pequenos aquelas cujo tempo semanal de dedicação aos afazeres domésticos é o mais elevado (ibid., p. 56)

Isso demonstra uma sobrecarga de trabalho das mulheres, já que elas têm ampliado sua participação no mercado de trabalho e ainda continuam arcando com a reprodução social, por meio do tempo dedicado ao domicílio e aos cuidados, enfrentando, assim, dificuldades para conciliar as responsabilidades familiares e profissionais. Este é um dos aspectos que implica o reconhecimento de políticas sociais de apoio às mulheres e sobretudo às famílias (BRUSCHINI, 2007, destaques das autoras). Este destaque às famílias ocorre, pois se considera que, embora essa problemática quase sempre afete principalmente as mulheres, "com as mudanças demográficas, econômicas e sociais das últimas décadas a tendência tem sido a de enxergar a questão como um problema da família e não somente das mulheres” (BRUSCHINI; RICOLDI, 2009, p. 121, destaques das autoras).

A OIT destaca que as esferas família e trabalho afetam-se mutuamente, uma vez que "as pessoas precisam trabalhar e gerar renda para satisfazer suas necessidades econômicas (pessoais e de suas famílias) e, ao mesmo tempo, cuidar da família e desempenhar tarefas domésticas não remuneradas em seus lares" (OIT, 2009a, p. 1). A preocupação da OIT no que se refere às responsabilidades familiares pode ser verificada em vários documentos. Entretanto, como preocupação específica surge na década de 1960, associada à maciça entrada das mulheres no mercado de trabalho. Nessa direção encaminhou a Convenção $156^{6}$, que prevê a igualdade de oportunidade e tratamento entre trabalhadores e trabalhadoras e estabelece obrigações entre os Estados. A Convenção determina aos Estados-membros incluírem, entre os objetivos de sua política nacional, o de permitir a homens e mulheres com responsabilidades familiares exercer o direito de estarem empregados, livres de discriminação e, na medida do possível, que

\footnotetext{
${ }^{6}$ A Convenção 156/81 da OIT que prevê a Igualdade de oportunidades de tratamento para trabalhadores e trabalhadoras com responsabilidades familiares foi ratificada por 40 países, dentre eles sete da América do Sul (Argentina, Bolívia, Chile, Paraguai, Peru, Uruguai e Venezuela), exceto o Brasil que é o único país do Mercosul que ainda não aderiu, apesar de esforços serem despendidos a favor da ratificação. Dentre eles destaca-se o envio da referida convenção, em janeiro de 2010, à Casa Civil para submissão no Congresso Nacional.

Serv. Soc. \& Saúde, Campinas, SP v. 14, n. 1 (19), p. 105-118, jan./jun. 2015 ISSN 1676-6806
} 
possam conciliar o trabalho remunerado com o doméstico. Também faz referência à necessidade de serem adotadas medidas de planejamento local e regional, considerando as necessidades e demandas desse grupo de trabalhadores, assim como o desenvolvimento de serviços públicos e privados de assistência à infância e às famílias (OIT, 2009b).

Os estudos de Cromptom e Lyonette (2007) mostram que na União Europeia, onde o equilíbrio entre trabalho-vida familiar é uma prioridade, pode-se observar variações na assistência que os governos têm oferecido às famílias com dois provedores. As autoras destacam que as formas como se atinge o equilíbrio entre trabalho e vida familiar e o grau de sucesso não dependem exclusivamente de programas governamentais. Outros fatores têm impacto significativo, como as horas semanais de trabalho, as relações de gênero, a classe social, idade, a presença ou não de filhos no lar e a divisão do trabalho doméstico entre os casais. Ou seja, os níveis de conflito entre trabalho e vida familiar variam de país para país e se relacionam com a articulação entre os fatores mencionados.

Frequentemente, estas questões são abordadas por um viés mais prático: “isto é, se os casais, de um modo ou de outro, conseguem combinar o rendimento duplo com as responsabilidades com a família, supõe-se que chegaram a um "equilíbrio"” (CROMPTOM; LYONETTE, 2007, p. 102). No entanto, os níveis de conflito são variados em virtude das inúmeras pressões e tensões implícitas na articulação entre emprego e obrigações familiares e das circunstâncias nacionais, individuais e familiares. Aquelas autoras, ao analisarem o conflito entre trabalho e vida familiar em alguns países da Europa, destacam na Grã-Bretanha a ausência relativa de apoio externo às famílias com duas fontes de renda e com fraca regulamentação do mercado de trabalho, o que contribui para maiores índices de conflito naquele país. Os conflitos são diminuídos em países como a Finlândia e a Noruega, onde a oferta de apoio do governo é maior. Destaca-se, então, que o apoio do Estado é uma condição necessária para um equilíbrio entre as duas esferas, embora não seja a única (CROMPTOM; LYONETTE, 2007).

Ao discorrer sobre este conflito na América Latina, Arriagada (2007) ressalta que

[...] na América Latina, as famílias cumprem funções de apoio social e amparo diante de crises econômicas, do desemprego, da enfermidade e da morte dos seus membros. A família como capital social é recurso estratégico de grande valor, uma vez que a limitada cobertura social em alguns países da região (no trabalho, na saúde, na seguridade 
social) a situa como a única instituição de amparo social diante de eventos traumáticos. Além disso, é a instituição que se encarrega das crianças, dos idosos, dos doentes e das pessoas portadoras de necessidades especiais (ibid., p. 255).

A partir desse enfoque, a autora destaca a necessidade de políticas dirigidas para os pais (homens e mulheres) e para instituições sociais, que devem apoiar as famílias na conciliação entre trabalho e família, assim como apoiar no cuidado dos filhos e idosos (ARRIAGADA, 2007).

Sobre essa discussão, Ricoldi (2010) esclarece que a noção de articulação entre família e trabalho remete às políticas públicas e privadas elaboradas com o objetivo de possibilitar a conciliação dos impasses originados do conflito entre trabalho e responsabilidade familiar dos trabalhadores e trabalhadoras, ou seja, remete às dificuldades e tensões que as famílias encontram, em seu cotidiano, para equilibrar estes dois espaços: a vida laboral e a vida familiar.

Conforme Sorj (2004), o Brasil não está entre os países que ratificaram a Works with Family Responsabilities Convention adotada em 1981, bem como não há reconhecimento de que a articulação entre a esfera do trabalho e as responsabilidades familiares constitua um problema social. As medidas de conciliação entre trabalho e família passam pela legislação trabalhista estabelecida para os trabalhos com contrato formal, que prevê, por exemplo, férias remuneradas e licenças maternidade e paternidade. Sobre este aspecto, Sorj (2004) destaca que, à medida que são beneficiados os trabalhadores com contratos formalizados, exclui-se a maioria dos trabalhadores brasileiros, e esta legislação concentra os benefícios na fase produtiva, não facilitando o equilíbrio entre trabalho e família no decorrer da vida laboral.

Sorj (2004) aponta algumas medidas de apoio às famílias que facilitam a conciliação entre trabalho e responsabilidades familiares: o serviço doméstico, do qual fazem uso as famílias mais abastadas; o acesso das crianças às creches e pré-escolas; a legislação trabalhista; os contratos e convenções coletivas de trabalho firmados entre empregados e empregadores; a flexibilidade da jornada de trabalho nos segmentos formalizados e as transferências de renda para as famílias por meio de programas governamentais de assistência social à população mais vulnerável. 


\section{CONSIDERAÇÕES FINAIS}

O debate sobre a questão da conciliação trabalho e vida familiar vem se tornando cada vez mais necessário, à medida que afeta a maioria das famílias. Este trabalho apenas colocou em cena algumas considerações sobre o tema, tendo em vista o incipiente debate no âmbito da sociedade brasileira, particularmente no campo do Serviço Social. Instigar este debate no campo profissional é urgente, pois os assistentes sociais se defrontam cotidianamente com os conflitos gerados nas relações entre o mundo do trabalho e o mundo da família, os quais são inseridos no campo das políticas de seguridade social, que têm exaltado o papel da família na proteção de seus membros. É um debate a ser aprofundado a partir das diferentes perspectivas teóricometodológicas sob as quais se desenvolve e que, obviamente, alinham-se a diferentes projetos societários. A discussão qualificada dessa questão é fundamental, considerando o projeto ético-político da profissão comprometido com a classe trabalhadora.

Recebido em 22.06.2015 - Aprovado em 26.06.2015

\section{REFERÊNCIAS}

ALENCAR. M. M. T. de. Transformações econômicas e sociais no Brasil dos anos 1990 e seu impacto no âmbito da família. In: Política social, família e juventude: uma questão de direitos. SALES, M.A; MATOS, M.C de; LEAL, M.C (Orgs.) 6. ed. São Paulo: Cortez, 2010. p. 61-81.

ANTUNES, R. Adeus ao trabalho? Ensaio sobre as metamorfoses e a centralidade do mundo do trabalho. 4. ed. São Paulo: Cortez; Campinas, SP: Editora da Universidade Estadual de Campinas, 1997.

ASTELARRA, J. Políticas públicas e divisão entre trabalho remunerado e não remunerado na Espanha. In: ARAÚJO, C; PICANÇO, F; SCALON, C (Orgs.). Novas conciliações e antigas tensões? Gênero, família e trabalho em perspectiva comparada. Bauru, SP: EDUSC, 2007. p. 59-95.

ARRIAGADA, I. Estruturas familiares, trabalho e bem-estar na América Latina. In:

ARAÚJO, C.; PICANÇO, F.; SCALON, C. (Orgs.). Novas conciliações e antigas Serv. Soc. \& Saúde, Campinas, SP v.14, n.1(19), p. 105-118, jan./jun. 2015 ISSN 1676-6806 
tensões? Gênero, família e trabalho em perspectiva comparada. Bauru, SP: EDUSC, 2007. p. 223-265.

BRAVERMAN, H. Trabalho e Capital Monopolista. Rio de Janeiro: Zahar Editores, 1976.

BRUSCHINI, C. Trabalho doméstico: inatividade econômica ou trabalho remunerado. In: ARAÚJO, C.; PICANÇO, F.; SCALON, C. (Orgs.). Novas conciliações e antigas tensões? Gênero, família e trabalho em perspectiva comparada. Bauru, SP: EDUSC, 2007. p. 21-58.

BRUSCHINI, M. C. A.; RICOLDI, A. M.. Família e trabalho: difícil conciliação para mães trabalhadoras de baixa renda. Cadernos de Pesquisa, São Paulo v. 39, n. 136, p. 93-123. jan/abr. 2009.

CAMPOS, M. S.; MIOTO, R. C. T. Política de Assistência Social e a posição da família na política social brasileira. Revista Ser Social, Brasília, n. 12, p. 165-190, 2003.

CROMPTON, R.; LYONETTE, C. "Equilíbrio" entre trabalho e vida na Grã-Bretanha e na Europa. In: ARAÚJO, C.; PICANÇO, F.; SCALON, C. (Orgs.). Novas conciliações e antigas tensões? Gênero, família e trabalho em perspectiva comparada. Bauru, SP: EDUSC, 2007. p. 99-131.

ESPING-ANDERSEN, G. Fundamentos sociales de las economias postindustriales. Barcelona: Ariel, 2000.

MARTIN, C. Os limites da Protecção da Família: introdução a uma discussão sobre as novas solidariedades na relação Família-Estado. Revista Crítica de Ciências Sociais, Coimbra, n. 42, p. 53-76, 1995.

MELO, H. P. et. al.. O setor serviços no Brasil: uma visão global - 1985/95. In: Texto para discussão n. 549. Rio de Janeiro: IPEA, 1998.

MIOTO, R. C. Processos de responsabilização das famílias no contexto dos serviços públicos: notas introdutórias. In: SARMENTO, H. B. M. Serviço Social: questões contemporâneas. Florianópolis: UFSC, 2012. p. 125-136.

MIOTO, R. C. Família e políticas sociais. In: BOSCHETTI, I. et al. Política social no capitalismo: tendências contemporâneas. São Paulo: Cortez, 2008. p. 130-148.

ORGANIZAÇÃO INTERNACIONAL DO TRABALHO. Trabalho e responsabilidades familiares: novos enfoques. In: Notas da OIT sobre trabalho e família. Brasília, 2009a. 
ORGANIZAÇÃO INTERNACIONAL DO TRABALHO. Trabalho e família: rumo a novas formas de conciliação com co-responsabilidade social. Relatório. Brasília: OIT, $2009 b$

RICOLDI, A. M. A noção de articulação entre trabalho e família e políticas de apoio. Nota Técnica. Mercado de Trabalho. Brasília: IPEA n. 42, p. 37-43, 2010.

SARACENO, C.; NALDINI, M. Sociologia da família. Tradução: Isabel Teresa Santos. Lisboa: Estampa, 1996.

SOARES, L. T. Os custos sociais do Ajuste Neoliberal na América Latina. 2. ed. São Paulo: Cortez, 2002.

SORJ, B. Trabalho e responsabilidades familiares: um estudo sobre o Brasil. Brasília: OIT, 2004. (Relatório final). 
Serv. Soc. \& Saúde, Campinas, SP v. 14, n. 1 (19), p. 105-118, jan./jun. 2015 ISSN 1676-6806 